would expect some day-to-day variation. Paterson and Lawrence (1972), in a study of 42 women, concluded that this was so. We too have found considerable day-to-day variation in healthy adults. The values tended to fall during the first part of the week, perhaps a consequence of the relatively sedentary nature of hospital work after the activity of the weekend. Marked increases could usually be related to increased exercise-for example, squash playing. The day-to-day variation is obviously important in assessing the significance of rises of serum CK from any cause. We have calculated that an increase should exceed $85 \%$ of the initial value to be significantly greater than variations seen in normally active adults. This criterion of significance would therefore tend to underestimate the significance of increases in patients at rest in bed.

The quality control data shows that with our manual method single estimations of enzyme activity have a coefficient of variation of $18 \%$ at $67 \mathrm{IU} / 1$. and $13 \%$ at $524 \mathrm{IU} / 1$. Thus, analytical variation makes a significant contribution to our criterion of significance. Future improved analytical methods will probably allow a smaller change in enzyme activity to be recognized as significant.

Though intramuscular injections might confuse the interpretation of serum CK (Hess et al., 1964; Cohen, 1972; Goldberg and Winfield, 1972) a review of the literature shows that very few drugs have been adequately studied. Marked increases of serum CK in six out of 14 patients after single injections of chlorpromazine have been well documented by Meltzer et al. (1970), who also showed increases in both subjects given an injection of phenobarbital. Fässler and Vorburger (1973) in a study of 24 subjects stated that "significant rises" of serum CK resulted from injection of diazepam and pentazocine, but details were not given of the magnitude or frequency of such rises. Batsakis et al. (1968) and Hess et al. (1967) found raised serum CK values in patients given frequent injections of penicillin, but no preinjection values were given. The diagnoses were not stated except in one patient who had pneumonia, a reported cause of raised CK values (Vélez-Garcia, 1966; Perkoff, 1968). Batsakis et al. (1968) also found raised values in four subjects receiving four-hourly injections of morphine, but no preinjection values were given and again the diagnoses were not stated. Chahine et al. (1974) showed that increases in serum CK after cardiac catheterization could be related to prior intramuscular injections of various drugs, but the effects of the individual drugs were not assessed.

We found that single injections of diamorphine and pentazocine cause significant increases of serum $C K$ values in about a quarter of patients (three out of 15 given pentazocine; three out of 10 given diamorphine). The greatest increase was from $64 \mathrm{IU}$ to $395 \mathrm{IU} / 1$. These two drugs are the analgesics most commonly used for myocardial infarction in this hospital and the increase in serum CK associated with their use could cause confusion in diagnosis. We suggest that when possible blood should be collected before the first injection to detect any early diagnostic increase of serum CK. Any subsequent rise must be interpreted with caution.

Despite the effects of exercise and of intramuscular injections on serum CK values, Goldberg and Winfield (1972) showed that serum $C K$ was the most reliable single enzyme test for the diagnosis of recent myocardial infarction. In the future it may be possible to measure the cardiac isoenzyme of CK routinely (Konttinen and Somer, 1973; Mercer, 1974). Meanwhile, consideration of the effects of exercise and injections along the lines we have suggested should lead to greater accuracy in diagnosis.

We thank Dr. R. B. Williams, senior registrar in pathology, for the collection of specimens from blood donors.

Requests for reprints should be addressed to K. E. Newton, Department of Chemical Pathology, St. James's Hospital, Leeds LS9 7TF.

\section{References}

Batsakis, J. G., et al. (1968). Clinical Biochemistry, 2, 125.

Campbell, D. G., and Owen, J. A. (1967). Clinical Biochemistry, 1, 3

Chahine, R. A., Eber, L. M., and Kattus, A. A. (1974). American Heart fournal, 87, 170 .

Cohen, L. (1972). Fournal of the American Medical Association, 219, 625.

Dalal, F. R., Cilley, J., jun., and Winsten, S. (1972). Clinical Chemistry, 18, 330.

Dubo, H., et al. (1967). Lancet, 2, 743.

Ebashi, S. L., et al. (1959). Fournal of Biochemistry, 46, 103.

Fässler, B., and Vorburger, C. (1973). Schweizerische medizinische Wochenschrift, 103, 311 .

Goldberg, D. M., and Winfield, D. A. (1972). British Heart fournal, 34, 597.

Griffiths, P. D. (1966). Clinica Chimica Acta, 13, 413.

Hess, J. W., et al. (1964). Annals of Internal Medicine, 61, 1015.

Hess, J. W., et al. (1967). Clinical Chemistry, 13, 994.

Konttinen, A., and Somer, H. (1973). British Medical fournal, 1, 386

Levell, M. J., and Payne, R. B. (1973). Diagnostica, No. 28, p. 10.

Meltzer, H. Y., Mrozach, S., and Boyer, M. (1970). American fournal of Medical Sciences, 259, 42 .

Mercer, D. W. (1974). Clinical Chemistry, 20, 36.

Oliver, I. T. (1955). Biochemical fournal, 61, 116

Paterson, Y., and Lawrence, E. F. (1972). Clinica Chimica Acta, 42, 131.

Payne, R. B., and Levell, M. J. (1968). Clinical Chemistry, 14, 172.

Perkoff, G. T. (1968). Archives of Internal Medicine, 122, 326.

Savignano, T., Hanok, A., and Kuo, J. (1969). American fournal of Clinical Pathology, 51, 76 .

Vejiajiva, A., and Teasdale, G. M. (1965). British Medical fournal, 1, 1653.

Vejajiva, A., and Teasdale, G. M. (1965). British Medical fournal, 1, 1653. 68, 636 .

Watkins, S. M., and Lewis, A. (1972). British Medical fournal, 3, 733.

\title{
Pruritic Effect of Bile Salts
}

\section{J. KIRBY， K. W. HEATON， J. L. BURTON}

British Medical fournal, 1974, 4, 693-695

\section{Summary}

The pruritic effect of purified bile salts has been tested by applying them to blister bases. All the salts tested were

\footnotetext{
University Department of Dermatology, Bristol Royal Infirmary, Bristol BS2 8HW

J. KIRBY, M.R.C.P., Registrar (Present address : Department of Dermatology, St. Bartholomew's Hospital, London)

J. L. BURTON, M.D., M.R.C.P., Consultant Dermatologist, Senior Lecturer

University Department of Medicine, Bristol Royal Infirmary, Bristol BS2 8HW

K. W. HEATON, M.D., F.R.C.P., Consultant Physician, Senior Lecturer
}

pruritogens, but the dihydroxy salts (especially unconjugated chenodeoxycholate) were more effective than the trihydroxy salts. This may explain the poor correlation between total serum bile salt concentration and pruritus in obstructive jaundice.

\section{Introduction}

The pruritus of obstructive jaundice is thought to be due to bile salt retention (Herndon, 1972). Several previous attempts to induce itching by applying bile salts to the skin have been unsuccessful, however (Brulé and Cottet, 1942; Schoenfield, 1969), and the correlation between serum bile salt concentration and pruritus is poor (Osborn et al., 1959; Datta and Sherlock, 1963; Neale et al., 1971). It seems likely that the various salts 
might differ in their ability to provoke pruritus, and we therefore tested the pruritic effect of purified bile salts by applying them directly to intact skin and to blister bases. We used the terms "bile salt" and "bile acid" interchangeably though in man the bile salts are mainly conjugated and ionized.

\section{Methods}

We tested 10 men and 14 women, aged 18-75 years (mean 45), who either were normal volunteers or had localized non-irritable dermatoses. None of the subjects had ever been jaundiced, and none complained of spontaneous itching.

The nine compounds tested were the purified sodium salts of the three main bile acids and their taurine and glycine conjugates (Maybridge Chemicals, Tintagel): cholate, deoxycholate, chenodeoxycholate, glycocholate, glycodeoxycholate, glycochenodeoxycholate, taurocholate, taurodeoxycholate, and taurochenodeoxycholate.

These compounds were each dissolved in phosphate buffered saline at $1 \mathrm{mmol} / \mathrm{l}$. concentration with the exception of the deoxycholate and chenodeoxycholate, which were insoluble in saline. These two compounds were first dissolved in 5\% sodium bicarbonate and then diluted with buffered saline to a bile salt concentration of $1 \mathrm{mmol} / \mathrm{l}$. The $\mathrm{pH}$ of all these final solutions was within the range $6 \cdot 9-7 \cdot 1$. This concentration was chosen because the serum bile salt concentration in obstructive jaundice is about $0.3 \mathrm{mmol} / \mathrm{l}$. (Osborn et al., 1959), and some allowance was made for the possibility of preferential binding of bile salts in the skin (Schoenfield et al., 1967).

Prick and Patch Tests. - In six subjects the most concentrated solutions of each bile salt were applied to the back under an occlusive dressing for 48 hours as conventional patch tests. Each bile salt was also tested by prick tests in the forearm skin in six subjects.

Blister Base Tests.-In 20 subjects the solutions were tested by applying them to the base of cantharidin-induced blisters on the ventral surface of the forearm, by the technique of Arthur and Shelley (1955). The vesicles were produced by the application of $0.2 \%$ cantharidin plasters to the skin for six hours on the evening before the experiment, and on the next morning each vesicle was carefully aspirated. Then $0.1 \mathrm{ml}$ of each test solution was injected under a blister roof and was washed out with normal saline after two minutes. Room temperature was constant at about $20^{\circ}-22^{\circ} \mathrm{C}$ and other interfering sensory stimuli were kept at a minimum. The subjects were told that some of the solutions might cause an abnormal sensation, and they were asked to describe what they felt at the end of the two-minute test period. As control solutions we used normal saline and papain (Sigma Labs. 16-40 B.A.E.E. units/mg) diluted 1/10. Each solution was tested singly in a double-blind way, and the order of testing was randomized.

\section{Results}

The results of the prick tests and patch tests were entirely negative, no pruritus or erythema being produced in any subjects.

In the blister base tests all of the bile salts produced pruritus in at least two patients (see table). The itch developed within 45 seconds of the injection and occurred in "waves" as an abnormal prickling sensation. In some subjects this progressed to a burning or stinging sensation which faded within five minutes of irrigating the blister with saline. The dihydroxy bile saltsdeoxycholate, chenodeoxycholate, glycodeoxycholate, glycochenodeoxycholate, taurodeoxycholate, and taurochenodeoxycholate-were more effective in causing pruritus than the trihydroxy salts-cholate, glycocholate, and taurocholate (see table). On pooling these results the trihydroxy salts caused pruritus in 11 out of 60 tests, and the dihydroxy salts produced an itch in 56 out of 120 tests. A $\chi^{2}$ test showed this to be a highly significant difference $(P<0.001)$, and the difference was greater
Pruritic Effect of Purified Bile Salts when Applied to Blister Bases. Results are Numbers of Subjects who developed Pruritis.

\begin{tabular}{|c|c|c|c|c|c|}
\hline & & & $\begin{array}{l}\text { Free } \\
\text { Acids }\end{array}$ & $\begin{array}{l}\text { Taurine } \\
\text { Conjugates }\end{array}$ & $\begin{array}{l}\text { Glycine } \\
\text { Conjugates }\end{array}$ \\
\hline $\begin{array}{l}\text { Cholate .. .. } \\
\text { Deoxycholate } \\
\text { Chenodeoxycholate }\end{array}$ & $\begin{array}{l}\cdots \\
\cdots\end{array}$ & $\because$ & $\begin{array}{r}4 \\
10 \\
17\end{array}$ & $\begin{array}{l}2 \\
8 \\
9\end{array}$ & $\begin{array}{l}5 \\
6 \\
6\end{array}$ \\
\hline
\end{tabular}

with the unconjugated salts than with the conjugated salts. The control saline injections produced no itching, but the papain caused pruritus in all 20 subjects.

\section{Discussion}

Previous attempts to induce itching with exogenous bile salts have been largely unsuccessful. The intravenous (Osborn et al., 1959; Brulé and Cottet, 1942) and oral (Carey, 1958) administration of cholate failed to produce an itch though crude bile salt ingestion did exacerbate pruritus in patients with biliary cirrhosis (Ahrens et al., 1950). Topical application (Brulé and Cottet, 1942; Schoenfield, 1969) and iontophoresis (Schoenfield, 1969) of bile salts into the skin have also failed to produce pruritus. Varadi (1974), however, has reported that crude bile when applied to keratin-stripped skin under occlusion at acid $\mathrm{pH}$ will cause pruritus though he found no pruritus was produced at neutral $\mathrm{pH}$. Our present observations show that purified bile salts at a concentration of $1 \mathrm{mmol} / \mathrm{l}$. can cause pruritus in human skin at neutral $\mathrm{pH}$, and the dihydroxy salts (particularly unconjugated chenodeoxycholate) are more effective pruritogens than the trihydroxy salts. Varadi (1974) also observed that chenodeoxycholate at acid $\mathrm{pH}$ was more effective than cholate in producing pruritus. The poor correlation between serum bile salt concentration and pruritus (Osborn et al., 1959; Datta and Sherlock, 1963; Neale et al., 1971) may thus be due to variation in bile salt composition. In complete cholestasis the deoxycholates, being secondary bile acids, disappear, the proportion of glycine-conjugated salts decreases, and the ratio of chenodeoxycholate to cholate tends to increase (Neale et al., 1971). Cholestyramine, which relieves the pruritus of obstructive jaundice (Carey and Williams, 1961), has been shown to bind dihydroxy salts preferentially (Johns and Bates, 1969, 1970). Changes in the relative proportion of dihydroxy salts such as unconjugated chenodeoxycholate might thus account for the discrepancy between total circulating bile salt concentration and pruritus. Bile salts have been recovered from the skin surface of jaundiced patients with pruritus (Schoenfield et al., 1967), and $85 \%$ of the recovered bile salts were in the unconjugated form.

The mechanism by which bile salts cause pruritus remains speculative. Unconjugated bile salts are toxic to a variety of tissue and cell preparations in vitro, and this non-specific cytotoxicity is thought to relate to their detergent effect on lipid membranes (Heaton, 1972). The dihydroxy salts are more toxic than the trihydroxy salts, and this increased toxicity correlates with their increased surface activity (Dreher et al., 1967). Chemical mediators of itching may act by directly depolarizing cutaneous nerves or by releasing endogenous pruritogens such as histamine or proteolytic enzymes. Bile salts liberate small amounts of histamine on perfusion of animal skin (Schachter, 1952), and blood histamine levels increase in experimental obstructive jaundice (Anrep and Barsoum, 1953), but the poor correlation between pruritus and plasma histamine in liver disease (Mitchell et al., 1954) and the poor therapeutic response to antihistamines suggests that histamine is not the major mediator of pruritus.

We thank the Medical Research Council and the Wellcome Trust for financial support. 


\section{References}

Ahrens, E. H., Jun., et al. (1950). Medicine, 29, 299. Anrep, G. V., and Barsoum, G. S. (1953). fournal of Physiology, 120, 427. Arthur, R. P., and Shelley, W. B. (1955). Fournal of Investigative Dermatology, 25,341 .

Brulé, M., and Cottet, J. (1942). La Presse Médicale, 50, 369.

Carey, J. B. (1958). Fournal of Clinical Investigation, 37, 1494

Carey, J. B., and Williams, G. (1961). Journal of the American Medical Assiciation, 176, 432.

Datta, D. V., and Sherlock, S. (1963). British Medical fournal, 1, 216.

Dreher, K. D., Schulman, J. H., and Hofmann, A. F. (1967). Fournal of Colloid and Interface Science, 25, 71 .

Heaton, K. W. (1972). Bile Salts in Health and Disease, p. 117. London, Churchill Livingstone.
Herndon, J. J. (1972). Archives of Internal Medicine, 130, 632.

Johns, W. H., and Bates, T. R. (1969). Fournal of Pharmaceutical Sciences, $58,179$.

Johns, W. H., and Bates, T. R. (1970). Fournal of Pharmaceutical Sciences, 59, 329.

Mitchell, R. G., Butt, H. R., and Code, C. F. (1954). Fournal of Clinical Investigation, 33, 1199.

Neale, G., et al. (1971). Gut, 12, 145

Osborn, E. C., et al. (1959). Lancet, 2, 1049.

Schachter, M. (1952). British Fournal of Pharmacology, 7, 646

Schoenfield, L. J. (1969). In Bile Salt Metabolism, ed. L. Schiff, p. 257. Springfield, Thomas.

Schoenfield, L. J., Sjovall, J., and Perman, E. (1967). Nature, 213, 93.

Varadi, D. P. (1974). Archives of Dermatology, 109, 678.

\title{
Neonatal Hyperthyroidism and Long-acting Thyroid Stimulator Protector
}

\author{
J. NUTT， F. CLARK， R. G. WELCH， R. HALL
}

British Medical fournal, 1974, 4, 695-696

\section{Summary}

Neonatal hyperthyroidism has been thought to result from transplacental passage of long-acting thyroid stimulator (L.A.T.S.) from a mother with Graves's disease. $A$ case is presented here in which no L.A.T.S. was detected in the mother or neonate but another immunoglobulin, L.A.T.S. protector, a specific human thyroid stimulator, was shown to be present in the mother's serum. This stimulator may have been the cause of the neonatal hyperthyroidism.

\section{Introduction}

Rosenberg et al. (1963) first suggested that neonatal hyperthyroidism might be caused by transplacental passage of longacting thyroid stimulator (L.A.T.S.). This immunoglobulin (IgG) is found in the serum of some patients with hyperthyroidism due to Graves's disease and has with few exceptions been present in the serum of both the mother and child in cases of neonatal hyperthyroidism. Thomson and Riley (1966), however, described a case in which L.A.T.S. was not detectable in the mother or child.

Adams and Kennedy (1967) noted the existence of another immunoglobulin in the serum of patients with Graves's disease, which they termed L.A.T.S. protector (L.A.T.S.P.), since it was able to compete with L.A.T.S. for binding to human thyroid fractions in vitro but did not stimulate mouse thyroid in the in-vivo McKenzie bioassay (Adams and Kennedy, 1971) or monkey thyroid (Knight and Adams, 1973). L.A.T.S.P. has been shown to stimulate human thyroid both in vivo (Adams et al., 1974) and in vitro (Kendall-Taylor, 1973; Shishiba et al., 1973), and since unlike L.A.T.S. it is present in most patients with Graves's disease (Stewart et al., 1973) it has been suggested that it is likely to be a human thyroid stimulator responsible for the hyperthyroidism of Graves's disease.

University Department of Medicine, Newcastle upon Tyne NE1 4LP J. NUTT, PH.D., Research Associate

We report a case of neonatal hyperthyroidism in which no L.A.T.S. could be detected in the mother or infant, but in which L.A.T.S.P. was present in the mother's serum.

\section{Patients}

The mother, aged 25 years, developed hyperthyroidism due to Graves's disease at the age of 12 , when her basal metabolic rate was $+45 \%$. She was treated initially with potassium perchlorate and later with carbimazole. She relapsed on several occasions when antithyroid drugs were withdrawn and at age 20 underwent a partial thyroidectomy. Thyroid tissue showed changes compatible with hyperthyroidism, including focal lymphocytic infiltration with formation of germinal centres but no Askanazy cell change. She remained euthyroid thereafter. Her baby was born when she was 23 years of age. Eye signs of Graves's disease were present throughout, consisting of bilateral exophthalmos and left-sided lid retraction, but these did not necessitate treatment. At no time was pretibial myxoedema observed though slight splenic enlargement was noted before the thyroidectomy.

The Child was born three weeks prematurely and weighed 2,180 g. At birth she was noted to be hyperkinetic, with a tachycardia of 140/ min when resting, staring eyes, and a goitre. A thyroid function test at 3 days confirmed hyperthyroidism and she was treated with carbimazole $2.5 \mathrm{mg}$ six-hourly and Lugol's iodine 1 drop eight-hourly from the tenth to 27 th days with marked clinical improvement. Treatment was then withdrawn. Fourteen days later there was clinical and biochemical evidence of relapse of the hyperthyroidism and treatment was reinstituted in decreasing doses till she was 9 months of age. Withdrawal was uneventful and she subsequently thrived.

\section{Methods}

Routine thyroid function tests included measurement of the serum protein-bound iodine (P.B.I.) on an AutoAnalyzer, residual thyroid hormone binding test (Thyopac-3; Amersham), and determination of the effective thyroxine ratio (E.T.R.; Mallinkrodt).

Thyroid-stimulating hormone (T.S.H.) was measured by radioimmunoassay using the method of Hall et al. (1971) with Medical Research Council H.T.S.H. 68/38 as standard. The thyrotrophin-releasing hormone test (T.R.H. test) was performed as described by Ormston et al. (1971). Thyroglobulin antibody levels were determined as described by Evered et al. (1973).

L.A.T.S. was measured using a modification of the McKenzie bioassay (Nutt et al., 1974). L.A.T.S.P. was measured as described by Adams and Kennedy (1967) using a partially purified thyroid fraction of L.A.T.S. absorbing activity(L.A.A.). This was 